\title{
Association between family history and prognosis of patients with colorectal cancer: a systematic review and meta-analysis
}

\author{
Peiwei $\mathrm{Li}^{1 *}$, Shuyan $\mathrm{Li}^{2 *}$, Jiamin Chen ${ }^{1}$, Liming Shao ${ }^{1}$, Xinliang $\mathrm{Lu}^{1}$, Jianting Cai ${ }^{1}$ \\ ${ }^{1}$ Department of Gastroenterology, The Second Affiliated Hospital, Zhejiang University School of Medicine, Hangzhou, China; ${ }^{2}$ Department of \\ Nursing, The Second Affiliated Hospital, Zhejiang University School of Medicine, Hangzhou, China \\ Contributions: (I) Conception and design: X Lu, J Cai; (II) Administrative support: All authors; (III) Provision of study materials or patients: P Li, S \\ Li; (IV) Collection and assembly of data: P Li, S Li; (V) Data analysis and interpretation: P Li, J Chen, L Shao; (VI) Manuscript writing: All authors; \\ (VII) Final approval of manuscript: All authors. \\ "These authors contributed equally to this work. \\ Correspondence to: Xinliang Lu, MD. Department of Gastroenterology, The Second Affiliated Hospital, Zhejiang University College of Medicine, \\ Hangzhou 310009, China. Email: lux@zju.edu.cn; Jianting Cai, MD. Department of Gastroenterology, The Second Affiliated Hospital, Zhejiang \\ University College of Medicine, Hangzhou 310009, China. Email: jtcai6757@zju.edu.cn.
}

Background: A family history of colorectal cancer (CRC) increases the risk of developing CRC, and numerous studies have assessed the influence of family history on survival among CRC patients. However, the prognostic effect of a family history of CRC remains uncertain. The aim of this meta-analysis was to systematically assess the association between family history and CRC prognosis.

Methods: A comprehensive literature search was performed in the PubMed, Embase, Medline, Web of Science and Scopus databases up to October 2021, based on the Population, Intervention, Comparator, Outcomes and Study designs framework. Two reviewers independently extracted data on baseline characteristics and outcomes from the included studies. The Newcastle-Ottawa Scale was used for quality assessment of each study. Either a fixed- or a random-effects model was used to calculate the pooled hazard ratio (HR).

Results: Eighteen studies comprising 80,093 CRC patients were finally included in this meta-analysis. The Newcastle-Ottawa Scale scores of the included studies ranged from 4 to 8 , and 12 studies were of high quality. A significant association between family history and improved overall survival was determined in the $\mathrm{CRC}$ patients ( $\mathrm{HR}=0.89,95 \% \mathrm{CI}: 0.81-0.99)$ with significant heterogeneity $\left(\mathrm{I}^{2}=65.7 \%, \mathrm{P}<0.001\right)$. This effect was found in male CRC patients (HR 0.70, 95\% CI: 0.56-0.88) but not females (HR =0.77, 95\% CI: $0.54-1.09)$. The association between family history and disease-free survival was not significant $(\mathrm{HR}=0.94$, 95\% CI: 0.88-1.01) $\left(\mathrm{I}^{2}=21.0 \%, \mathrm{P}=0.263\right)$. However, a subgroup analysis supported the prognostic value of disease-free survival in patients with stage III CRC (pooled HR =0.78, 95\% CI: 0.67-0.92).

Discussion: In conclusion, a positive family history was associated with improved overall survival in CRC patients. It was also a favorable predictor of disease-free survival in patients with stage III CRC. These findings should be interpreted with caution because of limitations related to study quality and differences in the adjusted factors across studies.

Keywords: Colorectal cancer (CRC); family history; survival; meta-analysis

Submitted Aug 05, 2021. Accepted for publication Dec 03, 2021.

doi: $10.21037 /$ tcr-21-1546

View this article at: https://dx.doi.org/10.21037/tcr-21-1546 


\section{Introduction}

Colorectal cancer (CRC) remains one of the most common cancers worldwide (1). It accounts for approximately $9.8 \%$ of all cancers diagnosed, with approximately 1.88 million newly diagnosed cases and 915,880 deaths annually; in 2020, CRC was responsible for $9.2 \%$ of cancer-related deaths overall (1). A family history of CRC in first-degree relatives (FDRs) increases the risk of developing CRC by 2 - to 4 -fold (2). Individuals with a positive family history of CRC are also at higher risk of developing colorectal adenomas (3). The association between family history and the risk of CRC has been attributed to both genetic and environmental factors.

However, evidence of the association between a family history of CRC and the survival of CRC patients is inconsistent. Some studies reported improved survival in CRC patients with a positive family history (4-6), whereas other studies found no significant association (7). For example, a study of 2960 CRC patients found that family history was significantly associated with better overall survival (HR $=0.539,95 \%$ CI: 0.330-0.881) (8). In the study of Bass et al., a history of CRC in a FDR was associated with worse survival (HR $=1.32,95 \% \mathrm{CI}: 1.01-1.72)$ (9). This difference might have been due to differences in the study design, study population, or definition of family history. Thus, to assess the association between family history and CRC survival more systematically, we performed a systematic review and meta-analysis of studies examining this relationship. We present the following article in accordance with the PRISMA reporting checklist (available at https://tcr.amegroups.com/ article/view/10.21037/tcr-21-1546/rc) (10).

\section{Methods}

\section{Literature search and study selection}

The following Participants, Interventions, Comparison, Outcome and Study Design criteria were applied: (I) patients with CRC as the participants; (II) family history of CRC as the interventions (exposures); most but not all of the relevant studies defined a positive family history as having at least one first-degree relative (FDR) with CRC; (III) survival of patients with or without a family history of CRC (comparison); (IV) overall, disease-free survival and CRC-specific survival of CRC patients (outcome); and (V) cohort studies (study design). A comprehensive literature search was performed in the PubMed, Embase, Medline, Web of Science and Scopus databases up to October 2021. The following terms were used in the search procedure: ('family history' or 'aggregation' or 'familial' or 'family member' or 'first degree relative' or 'second degree relative' or 'first degree relatives' or 'second degree relatives') (in any field) AND ('colorectal cancer' or 'colon cancer' or 'rectal cancer' or 'colorectal adenocarcinoma' or 'colon adenocarcinoma' or 'rectal adenocarcinoma' or 'colorectal carcinoma' or 'colon carcinoma' or 'rectal carcinoma' or 'colorectal tumor' or 'colon tumor' or 'rectal tumor') (limited in title, abstract, or key words) AND ('survival' or 'prognosis' or 'prognostic' or 'mortality') (limited in title, abstract, or key words). References cited in the included studies and relevant reviews were also searched for potentially missed studies. The retrieved reports were carefully examined to exclude duplicate studies. The titles and abstracts of the selected articles were scanned, with the full articles subsequently reviewed to include eligible studies.

The eligibility of the studies for inclusion was evaluated independently by two investigators according to the following criteria: (I) cohort study, (II) the association between family history and CRC prognosis was evaluated, and (III) HRs and 95\% CIs were reported. The exclusion criteria were as follows: (I) reviews and conference papers and (II) articles written in languages other than English. The literature search and study inclusion were performed by one author (Peiwei Li), and another author (Shuyan $\mathrm{Li}$ ) assisted if there was any difficulty.

\section{Data extraction}

Two reviewers (Peiwei Li and Shuyan $\mathrm{Li}$ ) extracted the data, with discrepancies resolved by discussion or by a third investigator. The following information was extracted from each study: first author, publication year, study design, country of origin, sample size, age and sex of the participants, months of follow-up, cancer type and CRC stage, family history definition, risk estimates and adjusted factors. Ratios that reflected the greatest degree of control for potential confounders were used. The NewcastleOttawa Scale (NOS) was used for the quality assessment of each study (11). The maximum total score in the NOS is 9 , with a score of 6 or higher indicating high study quality.

\section{Statistical analysis}

Heterogeneity across individual studies was assessed by the chi-squared and $\mathrm{I}^{2}$ tests; $\mathrm{P} \leq 0.05$ and/or $\mathrm{I}^{2}>75 \%$ were considered to indicate significance (12). Pooled HRs and 
95\% CIs were calculated using a random-effects model if there was significant heterogeneity; otherwise, a fixedeffects model was applied. Most of the HRs extracted from the included studies were adjusted HRs, except for one study in which a crude HR was reported. Also, the factors age, sex, disease stage and tumor location were adjusted for in most of the analyses, as shown in Table 1. Other adjusted factors included body mass index, smoking, alcohol and tumor differentiation (Table 1). A primary meta-analysis was conducted to assess the associations of CRC family history with overall survival, disease-free survival and CRC-specific survival in CRC patients. Subgroup analyses and sensitivity analyses were then conducted to explore the sources of heterogeneity and to evaluate the potential modifying effect of factors such as definition of CRC family history, tumor location (colon or rectum), study design, country of origin, sex, sample size and CRC stage. Begg's funnel plots and Egger's test were used to explore publication bias risk. All analyses were conducted using Stata software (V.11.0; StataCorp, College Station, TX, USA). Statistical significance in all tests was defined as $\mathrm{P}<0.05$.

\section{Results}

\section{Description of the included studies}

The literature search yielded 4,352 potentially eligible studies, of which 34 were potentially relevant. Sixteen studies were excluded because they did not report the association between family history and CRC survival $(\mathrm{n}=6)$, were not original articles $(n=4)$, or contained insufficient data $(\mathrm{n}=6)$.

Finally, 18 studies comprising 80,093 CRC patients met the inclusion criteria for the meta-analysis (4-9,13-24). The selection process is presented in Figure 1 and the characteristics of the included studies in Table 1. Among the included studies, 6 were prospective studies and 12 retrospective studies. Only 4 studies were conducted in Asia, while the remaining 14 were performed in Western countries. The sample size of the included studies ranged from 112 to 31,801 . Most of the studies enrolled CRC patients with any disease stage, but four included only stage III CRC patients, two studies only colon cancer patients, and one study only patients with stages I-III CRC. For most of the included studies $(\mathrm{n}=13)$, a positive family history was defined as having at least one FDR with CRC. Other definitions of a positive family history were: at least one family member with CRC (14), parent or sibling with
CRC (16) and near relatives with CRC (24). One study did not provide a definition of family history (15). The NOS scores of the included studies ranged from 4 to 8 , and 12 studies were of high quality (Table S1).

\section{Association between family history and overall survival in $C R C$}

Seventeen studies assessed the association between family history and CRC overall survival in a total of 66,947 CRC patients. In the pooled analysis, the HR was $0.89(95 \%$ CI: 0.81-0.99), and there was significant heterogeneity $\left(\mathrm{I}^{2}=65.7 \%, \mathrm{P}<0.001\right)$ (Figure 2).

The results of the subgroup analyses are presented in Table 2. In those studies that defined a positive family history of CRC as a FDR with CRC, the pooled HR was 0.88 (95\% CI: 0.80-0.97); in studies using another definition of a positive family history, the HR was 1.31 (95\% CI: 0.47-3.59). The pooled HR for the association between a family history and overall survival in CRC patients was 0.70 (95\% CI: $0.56-0.88$ ) in males (Figure $3 A$ ) and 0.77 (95\% CI: 0.54-1.09) in females (Figure 3B), suggesting that a family history of CRC was associated with improved overall survival in males but not in females. In terms of the CRC stage, a positive family history was associated with better overall survival in patients with stage III CRC (pooled HR $=0.76,95 \%$ CI: 0.64-0.90), while there no significant association in patients with other CRC stages. The results of subgroup analyses performed according to tumor location, geographic region, study design and sample size are shown in Table 2. Subgroup analyses indicated that tumor location, geographic region, sex and sample size as the sources. For example, although the pooled analysis showed the significance of the association between family history and CRC overall survival $\left(\mathrm{I}^{2}=60.5 \%, \mathrm{P}=0.001\right)$, this did not apply to male patients $\left(\mathrm{I}^{2}=0 \%, \mathrm{P}=0.464\right)$.

\section{Association between family history and disease-free survival in CRC}

Eight studies involving 44,129 participants evaluated the influence of family history on the disease-free survival of patients with CRC. The pooled HR was 0.94 (95\% CI: $0.88-1.01)$, without significant heterogeneity $\left(\mathrm{I}^{2}=21.0 \%\right.$, $\mathrm{P}=0.263$ ) (Figure 4). In the sensitivity analysis, the pooled HR was 0.88 (95\% CI: 0.77-1.01) after excluding one study that did not define a positive family history as an FDR with CRC. Interestingly, family history was a favorable predictor 


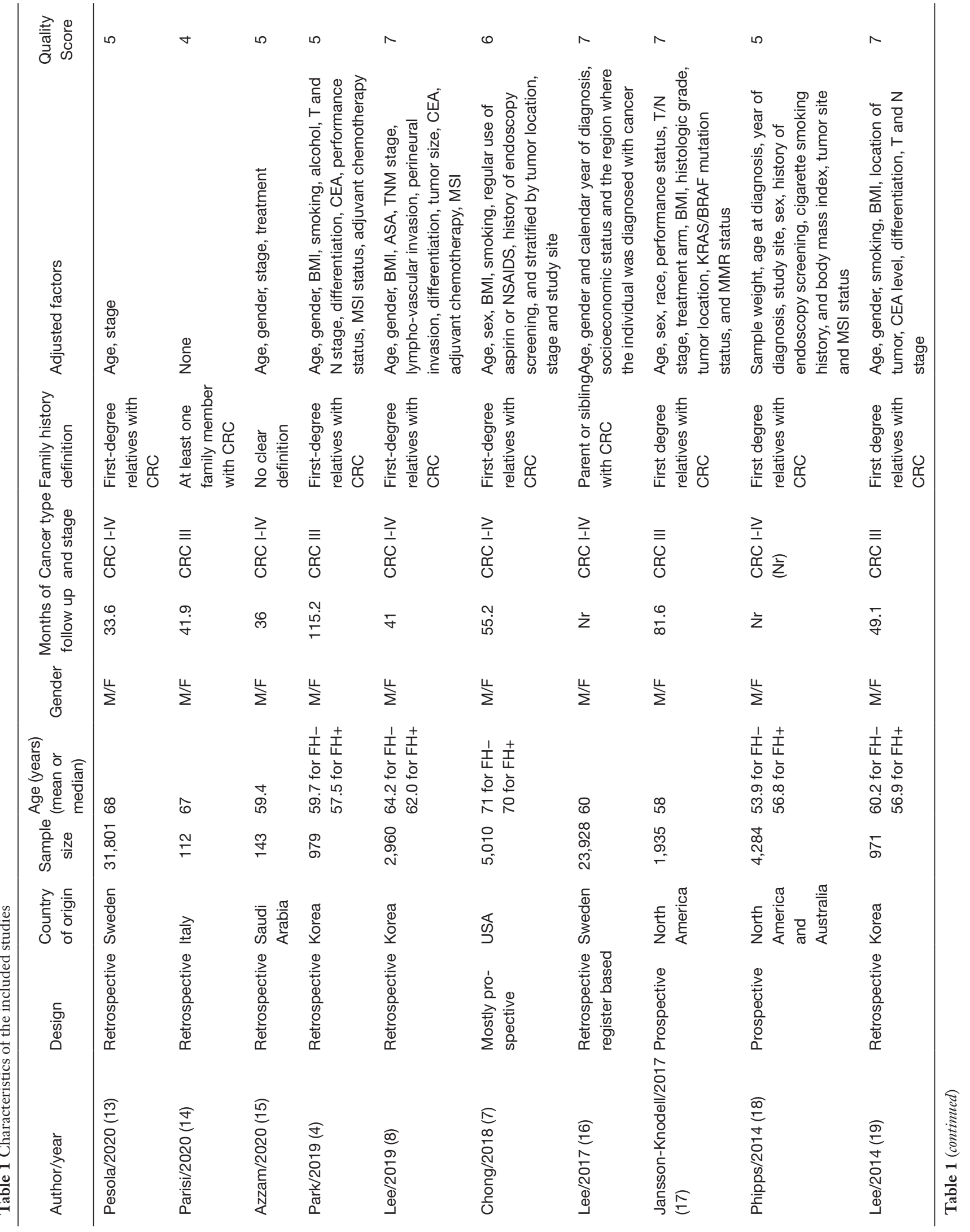




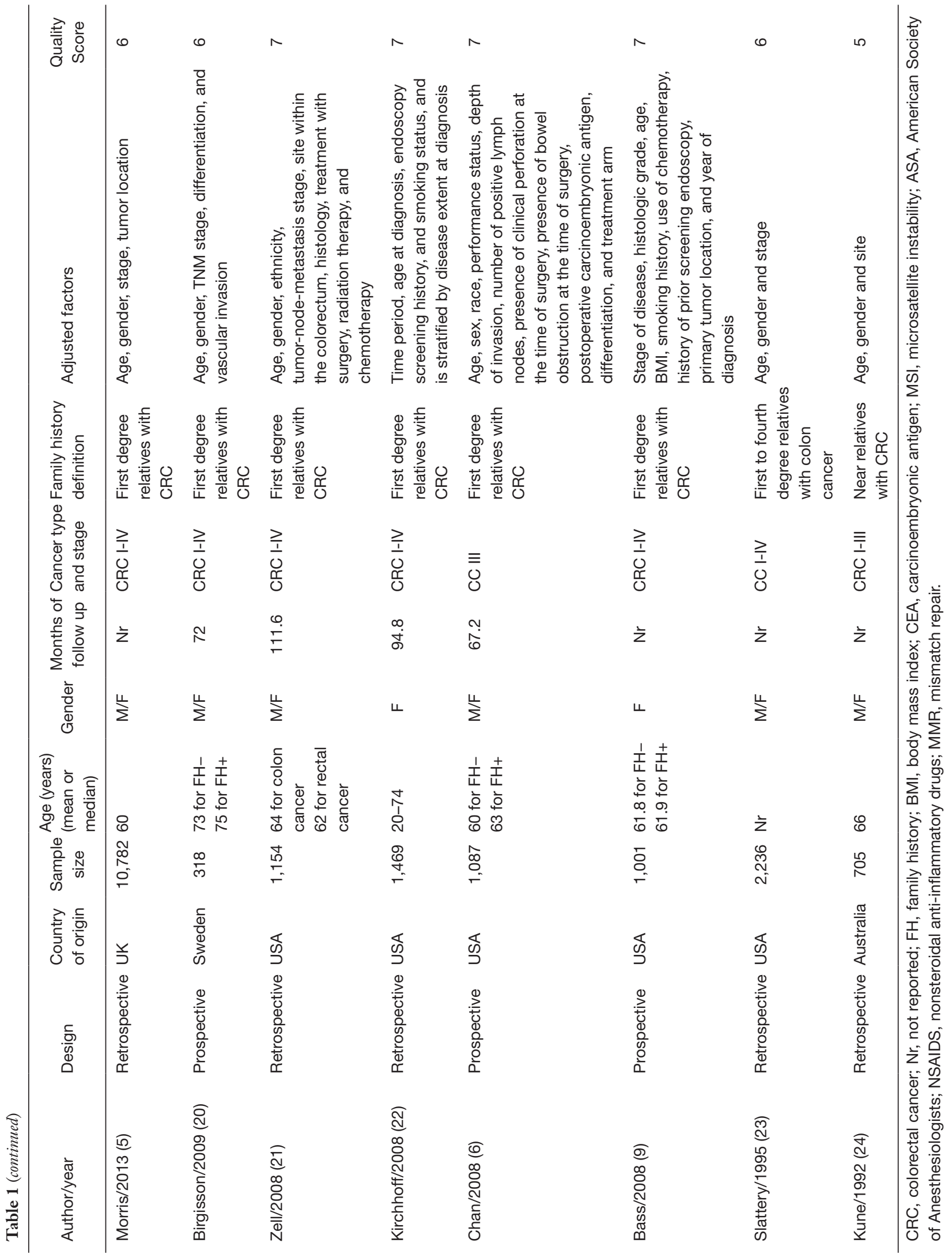




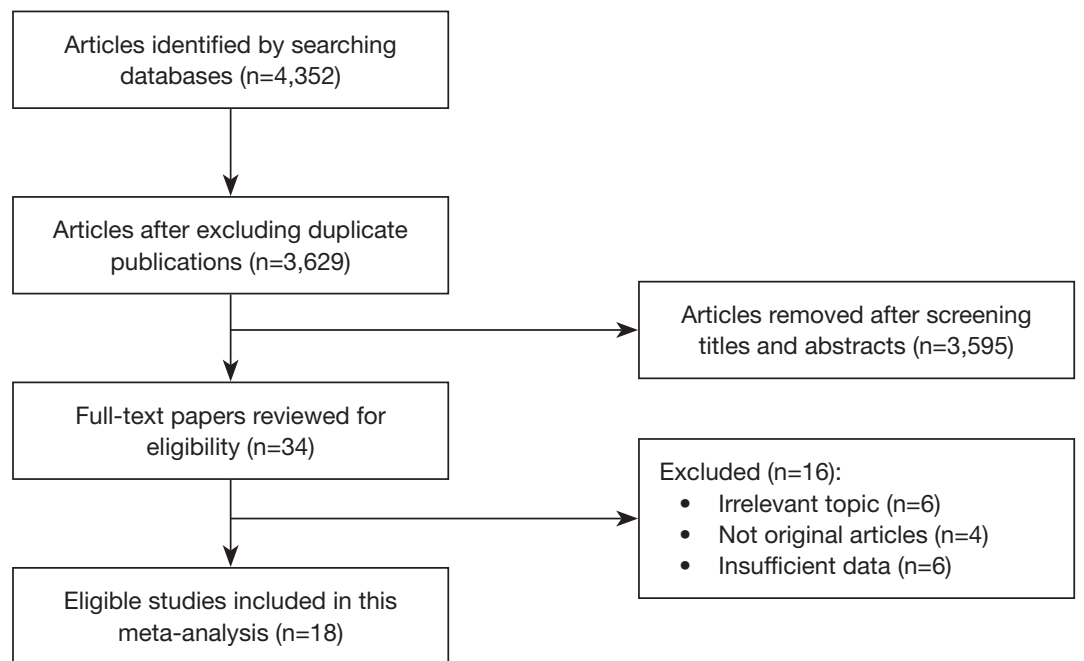

Figure 1 Flow diagram of the selection process.

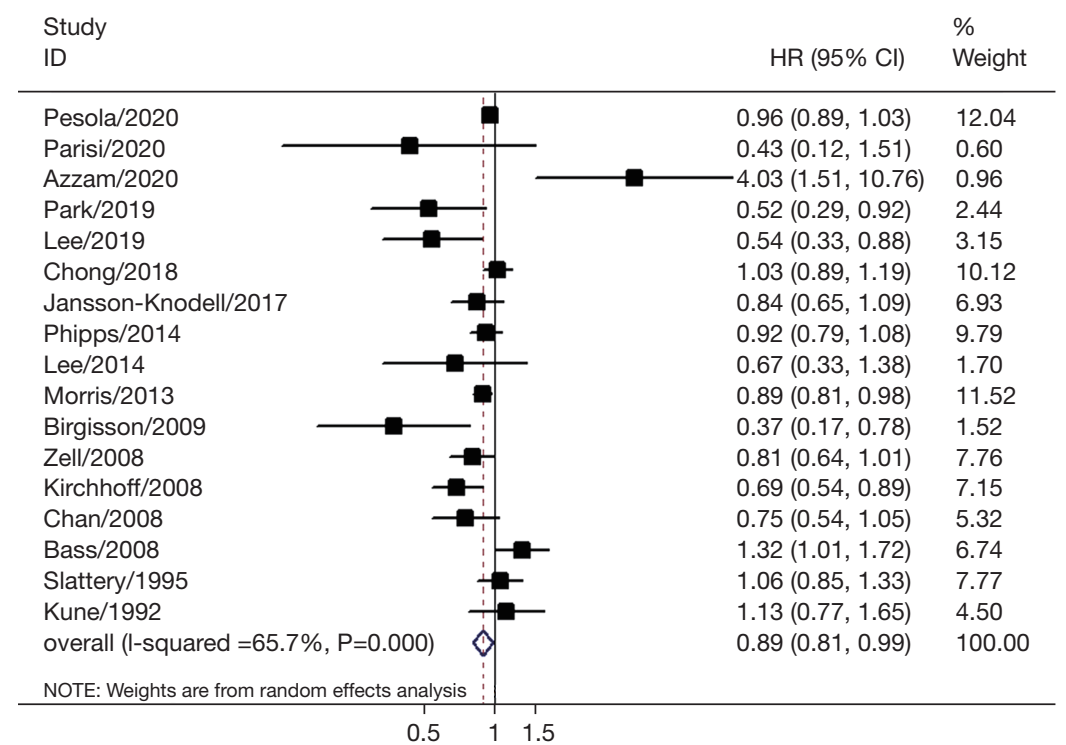

Figure 2 Forest plots for the association between family history and overall survival of CRC. CRC, colorectal cancer.

of disease-free survival among patients with stage III CRC (pooled HR =0.78, 95\% CI: 0.67-0.92).

\section{Association between family bistory and CRC-specific survival}

Based on the results of seven studies involving 35,116 patients, there was no significant association between a family history of CRC and CRC-specific survival (pooled $\mathrm{HR}=1.00,95 \%$ CI: 0.87-1.15).

\section{Publication bias}

Begg's funnel plots and Egger's tests suggested no evidence of publication bias in the present analyses.

\section{Discussion}

This meta-analysis was based on 18 studies evaluating the association between family history and overall survival, disease-free survival, or CRC-specific survival in CRC patients. The pooled results indicated that patients with a 
Table 2 Subgroup analyses results for the association between family history and CRC overall survival

\begin{tabular}{|c|c|c|c|c|}
\hline Factor & Pooled HR & $95 \% \mathrm{Cl}$ & $\mathrm{I}^{2}(\%)$ & $P$ \\
\hline \multicolumn{5}{|l|}{ Tumor location } \\
\hline Colon cancer & 0.91 & $0.80-1.04$ & 52.3 & 0.021 \\
\hline Rectal cancer & 0.84 & $0.66-1.07$ & 48.8 & 0.069 \\
\hline \multicolumn{5}{|l|}{ FH definition } \\
\hline FDR with $\mathrm{CRC}^{*}$ & 0.88 & $0.80-0.97$ & 63.5 & 0.001 \\
\hline Others & 1.31 & $0.47-3.59$ & 76.4 & 0.014 \\
\hline \multicolumn{5}{|l|}{ Stage } \\
\hline 1 & 0.54 & $0.28-1.04$ & 0 & 0.724 \\
\hline II & 0.67 & $0.41-1.09$ & 0 & 0.418 \\
\hline III & 0.76 & $0.64-0.90$ & 0 & 0.783 \\
\hline IV & 0.68 & $0.43-1.08$ & 12.4 & 0.285 \\
\hline \multicolumn{5}{|l|}{ Gender } \\
\hline Male & 0.70 & $0.56-0.88$ & 0 & 0.464 \\
\hline Female & 0.77 & $0.54-1.09$ & 78.6 & $<0.001$ \\
\hline \multicolumn{5}{|l|}{ Design } \\
\hline Prospective & 0.92 & $0.77-1.10$ & 68.4 & 0.007 \\
\hline Retrospective & 0.87 & $0.76-0.99$ & 66.5 & 0.001 \\
\hline \multicolumn{5}{|l|}{ Geographic region } \\
\hline Asia & 0.85 & $0.41-1.74$ & 79.0 & 0.003 \\
\hline Western & 0.92 & $0.84-1.00$ & 58.2 & 0.004 \\
\hline \multicolumn{5}{|l|}{ Sample size } \\
\hline Large & 0.94 & $0.89-0.99$ & 39.7 & 0.127 \\
\hline Small & 0.83 & $0.64-1.08$ & 73.9 & $<0.001$ \\
\hline
\end{tabular}

*, at least one FDR with CRC. FH, family history; CRC, colorectal cancer.

positive family history have a lower risk of overall mortality from CRC. This association was significant in male (HR $=0.70,95 \%$ CI: $0.56-0.88)$ but not female (HR $=0.77,95 \%$ CI: 0.54-1.09) patients. While there was no significant association between a family history of CRC and diseasefree or CRC-specific survival, the association of a family history of CRC with improved disease-free survival in patients with stage III CRC was significant ( $\mathrm{HR}=0.78,95 \%$ CI: 0.67-0.92).

A possible reason for the association between a family history of CRC and improved overall survival is that individuals with a family history of cancer might be more aware of their lifestyle choices. As reported in previous studies, a diagnosis of cancer in family members improves health-related lifestyle behaviours, including quitting smoking and increasing physical activity, thus improving survival in CRC patients (25). Moreover, individuals with a positive family history of CRC might undergo more frequent and careful screening, resulting in earlier detection of cancer and thus improved survival. However, most of the included studies adjusted for other patient and disease characteristics associated with survival, including TNM stage. Genetic differences between CRC patients with and those without a family history might also explain the survival difference. Some studies reported that CRC patients with a positive family history have a higher rate of a microsatellite instability-high status, which may be associated with better survival $(6,26)$. The effect of family history on the CRC prognosis is likely to be complex, influenced by both genetic and environmental factors, such that further studies are needed.

Several studies indicated that the association between family history and CRC prognosis is influenced by tumor location, with improved survival in patients with colon cancer but not rectal cancer $(20,21)$, or only in those with rectal cancer $(8,18)$. The differences in the clinical and molecular features of these two types of cancer (27) might account for the different prognostic effect of family history. In the current meta-analysis, there was no significant association between family history and overall survival in colon cancer or rectal cancer patients. Because of the limited number of studies ( $\mathrm{n}=10$ for colon cancer; $\mathrm{n}=7$ for rectal cancer), no valid conclusion could be made regarding the association between tumor location and prognostic role of family history on CRC. Our study found that the effect of family history on CRC survival was significant in male but not in female patients. Sex-based differences in competing risks, such as cardiac disease, pulmonary disease and diabetes mellitus, might explain this finding (21). Other possible reasons are differences in the lifestyle choices between males and females with a positive family history and in the treatment of male versus female patients, such as those requiring surgery for rectal cancer.

Regarding the definition of family history, most of the included studies defined family history as 'family history of CRC in a first-degree relative'. Other definitions were 'at least one family member with a history of CRC' and 'near relatives with CRC'. The results of the included studies were pooled before sensitivity analyses were performed; studies that did not use 'CRC in a first-degree relative' 


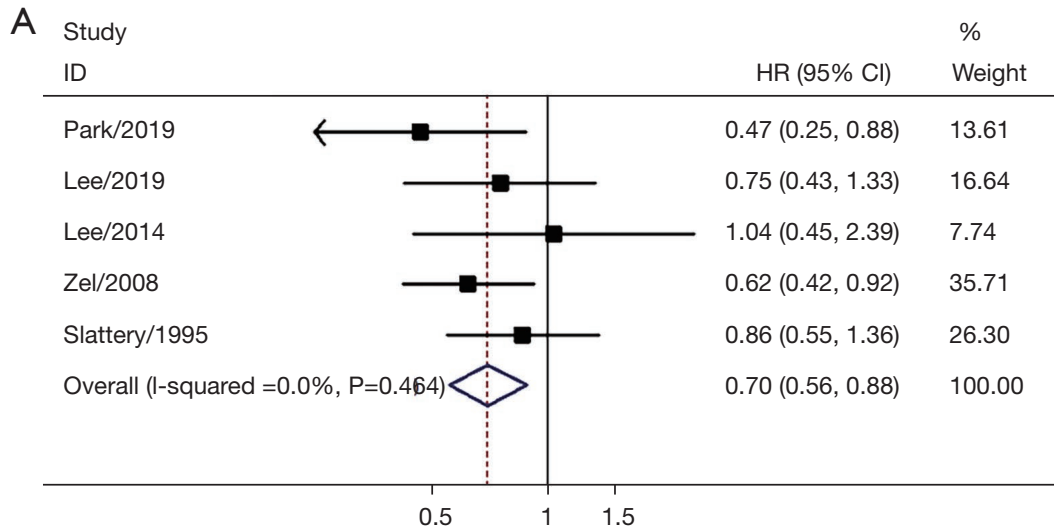

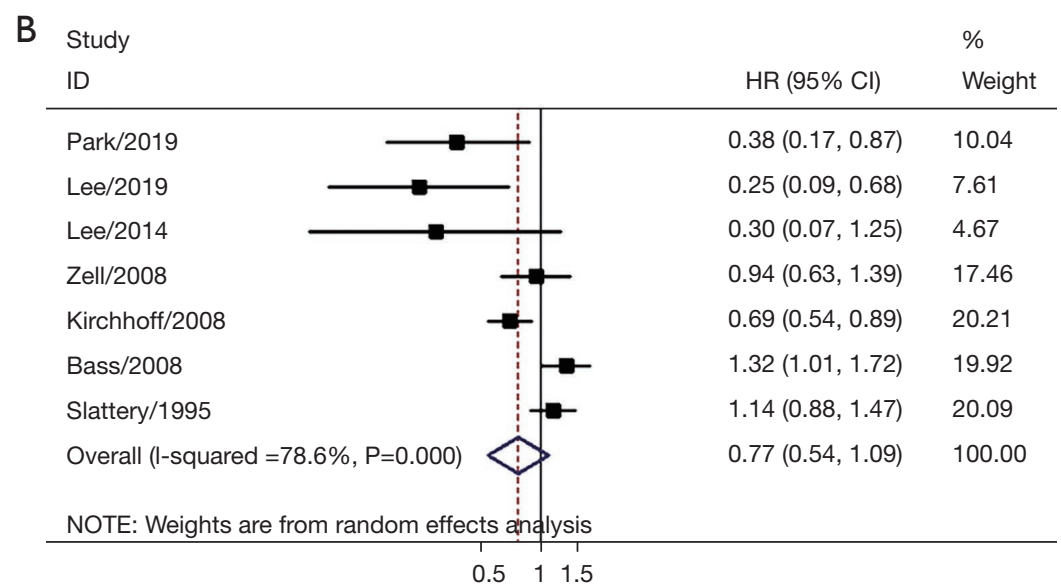

Figure 3 Subgroup analyses for the association between family history and overall survival of CRC. (A) Association between family history and survival of male CRC patients. (B) Association between family history and survival of female CRC patients. CRC, colorectal cancer.

\begin{tabular}{|c|c|c|}
\hline Study & & $\%$ \\
\hline ID & $\mathrm{HR}(95 \% \mathrm{Cl})$ & Weight \\
\hline Pesola/2020 & $0.98(0.91,1.06)$ & 78.40 \\
\hline Parisi/2020 & $0.80(0.33,1.95)$ & 0.58 \\
\hline Park/2019 & $0.68(0.42,1.09)$ & 2.01 \\
\hline Lee/2019 & $1.15(0.74,1.78)$ & 2.35 \\
\hline Jansson-Knodell/2017 & $0.87(0.69,1.10)$ & 8.39 \\
\hline Phipps/2014 & $0.82(0.48,1.38)$ & 1.64 \\
\hline Lee/2014 & $0.67(0.35,1.27)$ & 1.12 \\
\hline Chan/2008 & $0.72(0.54,0.96)$ & 5.51 \\
\hline Overall (I-squared $=21.0 \%, P=0.263)$ & $0.94(0.88,1.01)$ & 100.00 \\
\hline
\end{tabular}

Figure 4 Forest plots for the association between family history and disease-free survival of CRC. CRC, colorectal cancer. 
as the definition of family history were excluded. The similarity of the pooled results indicated that the definition of family history was not a source of heterogeneity; rather, subgroup analyses pointed to tumor location, geographic region, sex and sample size as the sources.

Our systematic review and meta-analysis comprehensively assessed observational data on the survival effect of family history on CRC patients. The pooled results indicated that a positive family history improved overall survival in this population. However, this study also had several limitations. First, the number of studies included in this meta-analysis was small, which may have affected the reliability of some of the subgroup analyses. Second, the included studies were limited to Asia, Europe, America and Australia. Third, the reasons for the heterogeneity could not be fully explained. Fourth, one-third of the included studies $(n=6)$ were of low quality, which may have compromised the pooled results. Fifth, the confounders in each study were not always the same, which might have caused bias in the risk estimates. Finally, most of the included studies were retrospective and were thus vulnerable to bias and confounding effects.

In conclusion, this systematic review and meta-analysis found that a positive family history of CRC was associated with improved overall survival in CRC patients. The prognostic effect of a family history was affected by sex and tumor stage. A family history was also a favorable predictor of disease-free survival among patients with stage III CRC. Further studies are warranted to explore the underlying mechanisms.

\section{Acknowledgments}

Funding: This study was funded by National Natural Science Foundation of China (Grant No. 81802881).

\section{Footnote}

Reporting Checklist: The authors have completed the PRISMA reporting checklist. Available at https://tcr. amegroups.com/article/view/10.21037/tcr-21-1546/rc

Conflicts of Interest: All authors have completed the ICMJE uniform disclosure form (available at https://tcr.amegroups. com/article/view/10.21037/tcr-21-1546/coif). The authors have no conflicts of interest to declare.

Ethical Statement: The authors are accountable for all aspects of the work in ensuring that questions related to the accuracy or integrity of any part of the work are appropriately investigated and resolved.

Open Access Statement: This is an Open Access article distributed in accordance with the Creative Commons Attribution-NonCommercial-NoDerivs 4.0 International License (CC BY-NC-ND 4.0), which permits the noncommercial replication and distribution of the article with the strict proviso that no changes or edits are made and the original work is properly cited (including links to both the formal publication through the relevant DOI and the license). See: https://creativecommons.org/licenses/by-nc-nd/4.0/.

\section{References}

1. Sung H, Ferlay J, Siegel RL, et al. Global Cancer Statistics 2020: GLOBOCAN Estimates of Incidence and Mortality Worldwide for 36 Cancers in 185 Countries. CA Cancer J Clin 2021;71:209-49.

2. Roos VH, Mangas-Sanjuan C, Rodriguez-Girondo M, et al. Effects of Family History on Relative and Absolute Risks for Colorectal Cancer: A Systematic Review and Meta-Analysis. Clin Gastroenterol Hepatol 2019;17:26572667.e9.

3. Samadder NJ, Curtin K, Tuohy TM, et al. Increased risk of colorectal neoplasia among family members of patients with colorectal cancer: a population-based study in Utah. Gastroenterology 2014;147:814-821.e5; quiz e15-6.

4. Park Y, Park SJ, Cheon JH, et al. Association of Family History With Cancer Recurrence, Survival, and the Incidence of Colorectal Adenoma in Patients With Colorectal Cancer. J Cancer Prev 2019;24:1-10.

5. Morris EJ, Penegar S, Whitehouse LE, et al. A retrospective observational study of the relationship between family history and survival from colorectal cancer. Br J Cancer 2013;108:1502-7.

6. Chan JA, Meyerhardt JA, Niedzwiecki D, et al. Association of family history with cancer recurrence and survival among patients with stage III colon cancer. JAMA 2008;299:2515-23.

7. Chong DQ, Banbury BL, Phipps AI, et al. Association of family history and survival in patients with colorectal cancer: a pooled analysis of eight epidemiologic studies. Cancer Med 2018;7:2192-9.

8. Lee SY, Kim DW, Kang SI, et al. Impact of Family History on Prognosis of Patients with Sporadic Colorectal Cancer. Ann Surg Oncol 2019;26:1118-26.

9. Bass AJ, Meyerhardt JA, Chan JA, et al. Family history 
and survival after colorectal cancer diagnosis. Cancer 2008;112:1222-9.

10. Moher D, Liberati A, Tetzlaff J, et al. Preferred reporting items for systematic reviews and meta-analyses: the PRISMA statement. PLoS Med 2009;6:e1000097.

11. Stang A. Critical evaluation of the Newcastle-Ottawa scale for the assessment of the quality of nonrandomized studies in meta-analyses. Eur J Epidemiol 2010;25:603-5.

12. Higgins JP, Thompson SG. Quantifying heterogeneity in a meta-analysis. Stat Med 2002;21:1539-58.

13. Pesola F, Eloranta S, Martling A, et al. Family history of colorectal cancer and survival: a Swedish population-based study. J Intern Med 2020;287:723-33.

14. Parisi A, Cortellini A, Venditti O, et al. Family History of Cancer as Potential Prognostic Factor in Stage III Colorectal Cancer: a Retrospective Monoinstitutional Study. J Gastrointest Cancer 2020;51:1094-101.

15. Azzam N, AlRuthia Y, Alharbi O, et al. Predictors of Survival Among Colorectal Cancer Patients in a Low Incidence Area. Cancer Manag Res 2020;12:451-9.

16. Lee M, Reilly M, Lindström LS, et al. Differences in survival for patients with familial and sporadic cancer. Int J Cancer 2017;140:581-90.

17. Jansson-Knodell CL, Foster NR, Sargent DJ, et al. Family history of colorectal cancer and its impact on survival in patients with resected stage III colon cancer: results from NCCTG Trial N0147 (Alliance). J Gastrointest Oncol 2017;8:1-11.

18. Phipps AI, Ahnen DJ, Campbell PT, et al. Family history of colorectal cancer is not associated with colorectal cancer survival regardless of microsatellite instability status. Cancer Epidemiol Biomarkers Prev 2014;23:1700-4. 19. Lee SD, Kim BC, Han KS, et al. Influence of family

Cite this article as: $\mathrm{Li} \mathrm{P}, \mathrm{Li} \mathrm{S}$, Chen J, Shao L, Lu X, Cai J. Association between family history and prognosis of patients with colorectal cancer: a systematic review and meta-analysis. Transl Cancer Res 2022;11(1):124-133. doi: 10.21037/tcr-21-1546 history on survival in patients with colon and rectal cancer. J Dig Dis 2014;15:108-15.

20. Birgisson H, Ghanipour A, Smedh K, et al. The correlation between a family history of colorectal cancer and survival of patients with colorectal cancer. Fam Cancer 2009;8:555-61.

21. Zell JA, Honda J, Ziogas A, et al. Survival after colorectal cancer diagnosis is associated with colorectal cancer family history. Cancer Epidemiol Biomarkers Prev 2008;17:3134-40.

22. Kirchhoff AC, Newcomb PA, Trentham-Dietz A, et al. Family history and colorectal cancer survival in women. Fam Cancer 2008;7:287-92.

23. Slattery ML, Kerber RA. The impact of family history of colon cancer on survival after diagnosis with colon cancer. Int J Epidemiol 1995;24:888-96.

24. Kune GA, Kune S, Watson LF. The effect of family history of cancer, religion, parity and migrant status on survival in colorectal cancer. The Melbourne Colorectal Cancer Study. Eur J Cancer 1992;28A:1484-7.

25. Humpel N, Magee C, Jones SC. The impact of a cancer diagnosis on the health behaviors of cancer survivors and their family and friends. Support Care Cancer 2007;15:621-30.

26. Gryfe R, Kim H, Hsieh ET, et al. Tumor microsatellite instability and clinical outcome in young patients with colorectal cancer. N Engl J Med 2000;342:69-77.

27. Liang JZ, Liang XL, Zhong LY, et al. Comparative Proteome Identifies Complement Component 3-Mediated Immune Response as Key Difference of Colon Adenocarcinoma and Rectal Adenocarcinoma. Front Oncol 2021;10:617890. 


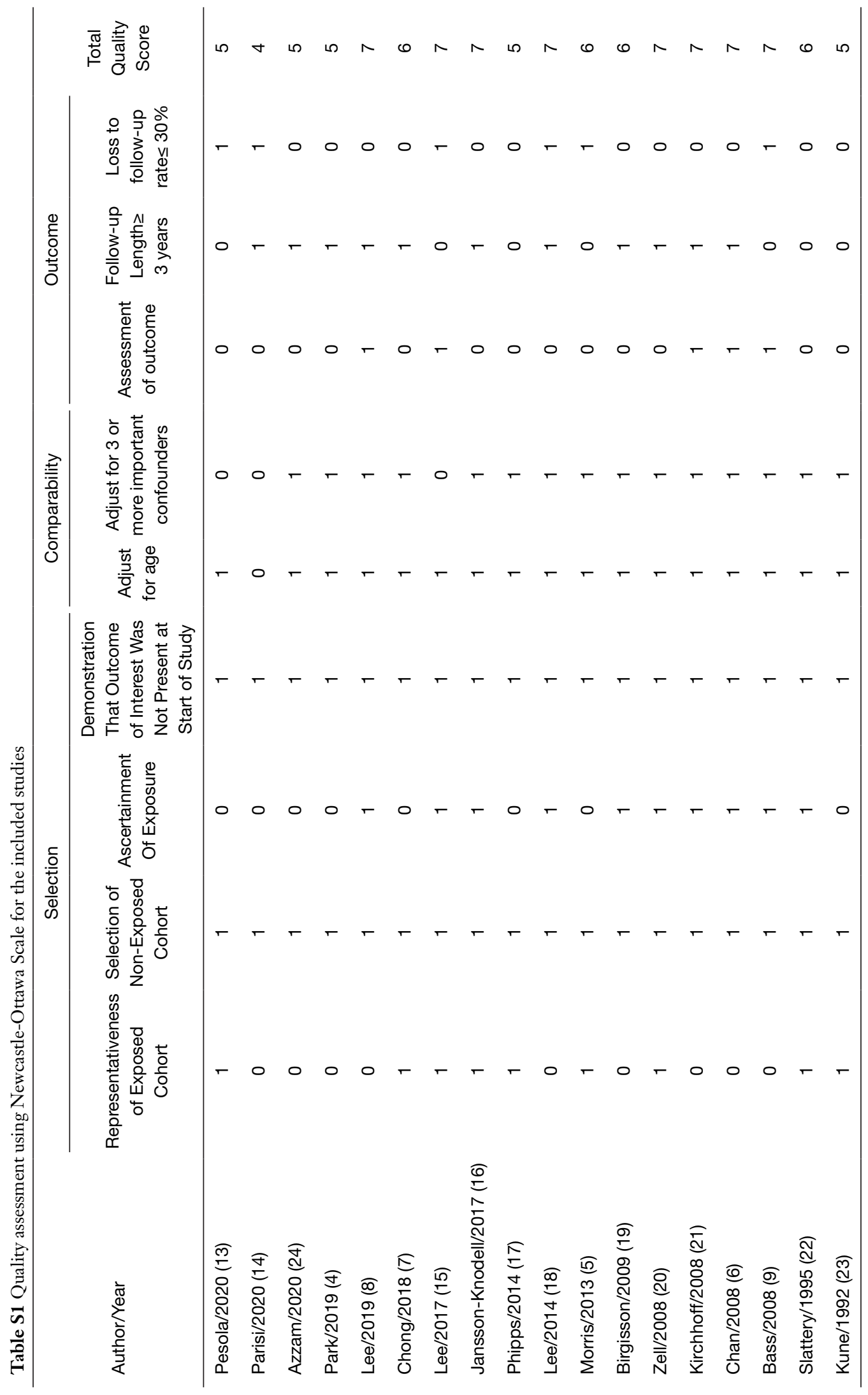

